This item was submitted to Loughborough's Research Repository by the author.

Items in Figshare are protected by copyright, with all rights reserved, unless otherwise indicated.

\title{
Geographies for play in austere times
}

PLEASE CITE THE PUBLISHED VERSION

http://dx.doi.org/10.1080/21594937.2015.1106051

\section{PUBLISHER}

(c) Taylor and Francis

\section{VERSION}

AM (Accepted Manuscript)

\section{PUBLISHER STATEMENT}

This work is made available according to the conditions of the Creative Commons Attribution-NonCommercialNoDerivatives 4.0 International (CC BY-NC-ND 4.0) licence. Full details of this licence are available at: https://creativecommons.org/licenses/by-nc-nd/4.0/

\section{LICENCE}

CC BY-NC-ND 4.0

\section{REPOSITORY RECORD}

McKendrick, John H., Peter Kraftl, Sarah Mills, Stefanie Gregorius, and Grace Sykes. 2019. "Geographies for Play in Austere Times". figshare. https://hdl.handle.net/2134/19372. 


\section{Geographies for play in austere times}

John H McKendrick ${ }^{1}$, Peter Kraftl ${ }^{2}$, Sarah Mills ${ }^{3}$, Stefanie Gregorius ${ }^{4}$ and Grace Sykes ${ }^{5}$

\section{Tensions eased, tensions raised: Play in contemporary UK}

Tim Gill describes the recent history of play in England as a "rollercoaster". This analogy has merit, and was the premise that gave rise to the seminar in Leicester, from which this collection of papers was derived. As Tim's paper details, and the others in this collection each suggest, the UK Government's commitment to children's play, unparalleled levels of investment, a strengthened national and regional play leadership, professionalisation of the playwork workforce (Skillsactive, 2010), and an ever more expansive evidence base to extol its value, took play to the top of the hill, only for post-austerity cuts to bring it right back down again.

Although the facts of the matter cannot be disputed, how these facts are to be regarded are open to multiple interpretations. It is perhaps the litmus test for whether a UK playworker is an optimist or a pessimist to ask their opinion of the recent history of play in the UK; the former will emphasise the progress made in the growth years and the legacy it has left behind; while the latter will bemoan the potential not realised of an English National Play Strategy (DCSF \& DCMS, 2008) and on-going disinvestment from play through local funding cuts. Some of the cuts, as Helen Woolley recounts in Sheffield, are a subtle scaling back of provision (such as the reduced opening hours at the Highfields Adventure Playground and the diversion away from playwork of the Rangers), while others are an unequivocal withdrawal of resource (such as the rationalisation of Sure Start centres).

What seems readily apparent from this collection of papers is that the new realities of play in times of austerity in the UK have brought to the fore a range of tensions that may have been supressed, or marginalised, in the era of investment. Although Tim Gill observes that the play sector became better at projecting a united front to its paymasters, some fundamental differences of opinion were never far away. Arthur Battram discusses one such issue - the choice between interventionist playwork (provision of resource-intensive environments that, as Alexandra Long and Tim Gill both recount, were the focus of much recent investment) and environmental playwork (the concern to dismantle barriers, such as transforming the street into a playspace that is championed by Alice Ferguson and Angie Page). Arthur seeks a third way, what he describes as strategic playwork, a holistic yet piecemeal approach that seeks the transformation of local culture to accommodate play. Rob Wheway is not averse to capitalising on opportunities that present through the scaling back of interventionist playwork investment; however, rather than promote 'street play', he would instead champion 'free play'. Without prejudicing through description either position as a problem, this might be conceived as a tension between the pragmatists (street play) and the fundamentalists (free play). Similar simmering tensions are evident between those who are primarily concerned to demonstrate the value of play for the attainment of a wide range of social goals and those who are more concerned to promote the inherent value of play. Alexandra Long's observation of the failure of the play sector to use the Best Play 'Play Objectives' (NPFA et al., 2000) as a framework to evaluate the impact of Big Lottery funded play projects, may be lamented and regretted by those who value play for its own sake. Then again, as Alexandra herself notes, there are already differences of opinion over whether play should be evaluated in terms of outcomes achieved or merely on facilitating access 
to play opportunities (which, in turn, would allow such outcomes to be achieved). Perhaps this highlights a crisis in the definition of play without which we may struggle to move forward in a united fashion. Or perhaps it simply highlights the need for increased collaboration and cross communication across play organisations, academia and local authorities to collate evidence and present powerful arguments for the importance of play. If so, there is a need to work together to ensure that children have access to play facilties whether this be purpose built infrastructure or the re-imaging and transformation of everyday spaces regardless of the differing reasons as to "why” we think play is important.

\section{Legacy of the 'investment years'}

Has, as Tim Gill suggests, the status of play plummeted in the UK? In the introductory note to this collection, we also referred to the derisory (and ill-informed) comments of the UK Minister with responsibility for play (Gove, 2013) and suggested that this may be indicative of play not being accorded the value that it warrants in Government, and beyond.

As noted above, Alexandra Long expresses concern that the sector has not grasped the opportunity to evidence the positive value of play. Although there is some evidence of new play infrastructure being laid to waste in the austerity cuts (Morton, 2011), there is no national understanding of whether this infrastructure persists as a positive physical legacy of the investment years; whether sustaining this infrastructure has been to the detriment of wider play provision; or whether the infrastructure has been allowed to fall. With more certainty, although Play England is a much smaller organisation after the cuts, it is without question a much stronger organisation than before the investment and one that provides much stronger support for play having benefited from it; the same can also be said of Play Scotland, Play Wales and Playboard NI. Although Tim Gill is concerned at the falling status of play, one legacy that persists from the early challenge of the UK Government to 'speak with a strong united voice' is that there is now much evidence of play fulfilling a role as a valuable ally to others.

\section{Play in service of society}

Some might worry that too much attention is paid to demonstrating the utility of play to achieving others' socially desirable goals, and that this endeavour might be at the expense of promoting the inherent value of play. Whether desirable or not, furthering alliances beyond play have had value to fend off the worst excesses of the 'austerity cuts', supporting those whose livelihood depends on play to sustain employment. Alliances have been forged across departments in local authorities (as Helen Woolley outlines for Sheffield) and across Third Sector organisations (as Tim Gill describes for Play England). The play sector continues to be skilled at demonstrating the wide range of benefits that can accrue from play and, as a result, secures money to support the on-going development of play (Conway, 2014).

Although we might question the sincerity of Government support for play, or indeed the level of understanding of the value of play in the claims that are made for it, across the UK play has been utilised as an integral part of key national social strategies. Tim Gill explains how the desire to respond to a very poor ranking on UNICEF's study of child well-being in rich nations (UNICEF, 2007) led to the UK Government investing more significant sums in play than the sector had envisaged. The Scottish Government's second annual review of progress on their Child Poverty Strategy for Scotland (Scottish Government, 2013) makes explicit reference to money invested in play through the Go Play and Go 2 Play programmes of Inspiring Scotland (Inspiring Scotland, nd), as an element of its anti-poverty strategy. An even more explicit 
articulation of the role of children's play in combatting child poverty has been articulated in Wales (Play Wales, nd). Play is valued for more than its play value and that is an opportunity upon which play can, does and should, capitalise.

\section{Play intelligence}

The utilisation of evidence to inform, or appraise, policy has a long history. In the 1990s, there was an intensification of evidence-based policy in the UK as the then Government sought to disassociate itself from interventions that were grounded in ideology, in preference for an approach that was defined by 'what works' (Boaz et al., 2008). In this context, Tim Gill's recollection of the challenge made by Chris Smith to articulate the value of play should come as no surprise, even if, as Tim suggests, the same Government Minister was already aware of the positive impact of play on children's lives in Islington (London).

Through Best Play, the play sector met the challenge set by the UK Government (NPFA et al., 2000). However, as Alexandra Long argues, it later fell short of demonstrating positive impact from the investment that followed. At times, evidence has worked against play; Helen Woolley reports how the community of the Pitsmoor Adventure Playground were poorly served by evidence that failed to account for the wider impact of the service it provided. At other times, evidence has worked for play; it was noted above how the UNICEF study of child well-being (UNCEF, 2007) was a catalyst for further investment through the Play Strategy. The play sector has also embraced evidence; Play Scotland has developed a toolkit through which local authorities and community groups can self-assess whether they "provide sufficient play opportunities in terms of quantity and quality" (Play Scotland, nd) and SkillsActive completed four annual surveys to better understand the character of the playwork workforce between 2003 and 2009 (Skillsactive, 2010).

What this clearly demonstrates is the need for the capacity within the play sector to generate, interpret and utilise evidence in support of play. Although not beyond the capabilities of playworkers (e.g. Smith, 2014), particularly when rich qualitative insight is valued as evidence from reflective practitioners, it does add another capacity to the desirable skill set of playworkers. Or, as this collection demonstrates, the need for playworkers to foster fruitful alliances with academia. Chris Martin's work with John McKendrick in this collection, may be an example of what can be achieved when the insight of playwork practitioners is brought together with the research expertise of academics. Although evidence alone is not a guarantor against disinvestment, and although powerful allies are needed among decision-makers (as Tim Gill recalls of his time engaging with Chris Smith), evidence can be a powerful ally.

There is also a need to conceive of evidence in the form of 'play intelligence', rather than merely 'information about play'. The sector was correct to warmly welcome the unprecedented $£ 235$ million of investment in children's play that was promised (if not delivered) through the DCSF's National Play Strategy in 2008. However, shared among over 11 million children in England (aged under 18), and spread over a three year period, this amounts to a little over $£ 7$ per child per year, or about 2p per child, per day; hardly a sum to transform the play fortunes of children in England. Even if we allowed that this investment was only to support the play of children aged 4-11 years old, it would still only amount to 4.5p per day over this three year period. What these calculations demonstrate is that there is a need for play data to be scrutinised and interpreted intelligently. While much would have been achieved with the sum of £235 million that was originally allocated for England's Play Strategy, critical analysis of the figures 
is needed to demonstrate the folly of over-stating its potential. More than ever in these leaner times, what is needed is play intelligence, rather than more information about play.

\section{Reconfiguring the geographies of playspace provision and decision-making}

Notwithstanding the limits to its transformative potential, the scaling back of the investment through the Play Strategy has generated uncertainty as to its geographical impact, across a range of contexts and geographical scales. What is clearer is that there are two dominant forces at work at the current time in the UK that are working toward alternative geographical outcomes. On one hand, as Helen Woolley recounts in Sheffield, there is rationalisation of play services and play facilities that is leading to less visible public landscapes, and material infrastructures, of play. Helen and Rob Wheway also note that this invisibility of public playspace has often exacerbated the peripheral siting of playspaces, to meet the misguided aim of preventing conflict or consternation at the perceived disruptiveness of play. Austerity cuts are giving impetus to this trend. On the other hand, there are pressures to recover everyday environments as playspaces, epitomised in the grassroots initiatives to reclaim the street as playspace (Alice Ferguson and Angie Page) and the desire of Rob Wheway to promote more 'free play', or in the thinking of Arthur Battram, to develop a play culture in which the everyday environment is valued and harnessed for the playspace opportunities it affords.

It is conceivable that the landscape of UK play provision will become a patchwork comprising localities with less visible commitment to playspace, while others have more visible commitment to playspace, at least for certain times within the week. Moving forward, the key issue is less of a concern to map the locational geography of play facilities; rather, it should be to focus on whether different implications follow from environments in which play provision is (i) embedded and omnipresent; (ii) segregated, by time and/or place; and (iii) absent in the landscape. The key geographical challenge that lies ahead is to articulate the impact of play provision on local play culture(s).

The highs that preceded the lows in England (as described by Tim Gill) were not quite as high in Wales, Scotland and Northern Ireland. Play has enjoyed a longer period of commitment from the Welsh Assembly Government, although the levels of investment have fallen far short of that enjoyed in England. In Scotland and Northern Ireland, devolved Government support for play has co-incided with austerity cuts to local Government provision. It may be more accurate in these parts of the UK to suggest that national support for play is, to a degree, off-setting local cuts that are being meted out at the current time. Indeed, at the macro-geographical level, John McKendrick and Chris Martin illustrate how playworkers' in SW England and Scotland in 2013 sense a very different context for play in their respective regions. There is now a complex play landscape in the UK. This complexity may prove to be a safeguard against the marginalisation of play. In the same manner that the Open Method of Co-ordination has been used in the EU to encourage different national Governments to adopt best practice in tackling child poverty (as nations are motivated not to be the least innovative and poorest performing) (Heidenreich and Zeitlin, 2009), so divergent pathways of play development and investment across the national regions in the UK might be used to 'drive up' standards. Equally, in these years of disinvestment from the UK Government, there may be political capital to be gained by devolved Governments of a different political hue adopting a more pro-play stance and positioning themselves squarely against the UK Government (Leith and McPhee, 2012).

Important as these national influences are, what lies ahead may be a less prominent role for both Central and Devolved Governments in the immediate future of play, at least in England. 
This return to 'localism' creates both opportunities and threats (Woolvin and Hardill, 2013). As Helen Woolley demonstrates in Sheffield, where local decision-making must be made under challenging fiscal conditions, communities are pitted against each other as they seek to protect their playspace and/or become 'investment-ready' in bidding for limited funding. On the other hand, allowing local people a greater say in determining the nature of their local worlds, has created a political environment that is, at least on temporary bases, conducive to the street play 'movement'. As for the geographies of provision, the shift to 'localism' also makes for greater complexity in play decision-making, it is, for instance, not without significance that the street play movement has drawn upon national play organisations and local academic partners to achieve its aims. This shift to localism may even throw up new possibilties for play; as Cindy Regalado outlines, 'playfulness' is an approach that engages adults and children, and facilitates their participation in action research to address local issues.

\section{Play cultures as our primary narrative}

As Alexandra Long, Tim Gill and Helen Woolley all indicate, articulating the impact of play was the focus for much of the 'investment years'. As with many project evaluations, this tends toward reductionist thinking, where the goal is to isolate the specific impact of a play intervention. Outcomes are the end goal, outputs are the deliverables through which these outcomes are achieved, and inputs are the mechanisms for effecting change - all of which are focused on specific play interventions. This compartmentalisation is consistent with an approach to play that is based on 'environmental playwork' and, perhaps even more so for 'intervention playwork'.

As Alexandra Long implores, Play UK must be able to 'talk the talk' if it is to secure funding for play. This need not, however, be the sum total of our concern to evidence the value of play. We must appreciate their competence in understanding their current situation, as "experts in their own lives" (Cahill, 2007 ), and therefore key players in this process. If Arthur Battram's 'strategic playwork' is a goal worthy of pursuit, then there needs to be a much stronger evidence base than there is at present to extol its value. Playworkers with their capacity to engage children clearly have the potential to work with them as co-producers of knowledge on play. Other challenges in articulating these play cultures must be faced. As Colin Ward articulated in his insight into the anarachic character of some everyday play (Ward, 1978) and as Sarah Holloway and Gill Valentine (2000) describe in their conceptualisation of the 'tribal child' as a means of understanding social studies of childhood, if these local play cultures are to be understood as something other than adult interpretations, then there are methodological and ethical challenges ahead. There remains much scope for a more fruitful partnership between play professionals and academics to better understand - in partnership with children - the everyday cultures of play. Once again, as Cindy Regalado suggests, there may even be a more leading role for 'play' in shaping how these engagements take shape.

\section{Concluding thoughts}

The starting point for the Leicester seminar was to question to what extent play was suffering from the 'austerity cuts' of the current UK Coalition administration. Each paper in this collection, although to varying degrees, acknowledges the challenges presented, and potential opportunities afforded, for play. Unlike in Scotland, and to a lesser extent Northern Ireland and Wales, these cuts in England have not been offset by a devolved Government that is outwardly supportive of play; on the contrary, the Government with responsibility in England has 
disinvested, failed to support, and demonstrated some hostility toward play. It would be remiss to ignore that these are trying times for playworkers (McKendrick et al., 2014) and play in the UK.

However, this pivotal historical moment for play in the UK demands more than lament and reactionary responses. Opportunities to reclaim play environments are being grasped (Alice Ferguson and Angie Page's street play). Play UK needs to re-articulate a future vision - be this promoting local play-oriented cultures as Arthur Battram would favour; championing 'free play' as Rob Wheway would favour; or positing play as everyone's ally - families, communities, practitioners and policy-makers alike. Presumably, it will be a vision of a play mix, rather than one wedded to a particular view.

The reality is that funding will not come easy, and may not return for a decade or more. However, play in the UK must be ready when it does return to articulate evidenced argument, as Alexandra Long and Tim Gill suggest, and this involves the need for play practitioners to embrace evaluation as part of their professional competencies (Smith, 2014). It may also be critical that play practitioners find allies across the professional child, youth and education disciplines, in forging more powerful, hopeful cross-disciplinary visions of childhood (Kraftl, 2013). Certainly, despite lean times, third sector organisations like the National Trust (2013) - in their 'Natural Childhood' initiative - have been able to join forces with major partners such as the NHS to offer a compelling, if rather nostalgic, case for outdoor play, education and exploration. Times may be tough, but in these and other ways, it is incumbent of the play sector to lay the foundations for the sector to capitalise on opportunities that lie further ahead.

\section{References}

Boaz, A., Grayson, L., Levitt, R. and Solesbury, W. (2008). "Does evidence-based policy work? Learning from the UK experience,” Evidence and Policy 4.2: 233-253.

Cahill, C. (2007). "Doing research with young people: participatory research and the rituals of collective work,” Children’s Geographies 5.3: 297-312.

Conway, M. (2014), “The thin of it - Surviving and thriving in austerity,” Journal of Playwork Practice 1: 87-91.

Department for Children, Schools and Families and Department for Culture, Media and Sport. (2008). The Play Strategy. London.

Gove, M. (2013). Michael Gove Speaks About the Importance of Teaching. September 13, 2013. Available at: https://www.gov.uk/government/speeches/michael-gove-speaks-about-theimportance-of-teaching [Accessed 14 November 2013].

Heidenreich, M. and Zeitlin, J. (eds) (2009). Changing European Employment and Welfare regimes: The influence of the Open Method of Coordination on national reforms. London: Routledge.

Holloway, S. and Valentine, G. (2000). "Spatiality and the new social studies of childhood," Sociology 34.4: 763-783.

Inspiring Scotland. (2013). “Go 2 Play.” Available online at: http://www.inspiringscotland.org.uk/our-funds/go-2-play [Accessed 22 November 2013].

Kraftl, P. (2013). Geographies of Alternative Education: Diverse Learning Spaces for Children and Young People. Bristol: Policy Press.

Leith, M. and McPhee, I. (eds). (2012). Scottish Devolution and Social Policy: Evidence from the First Decade. Cambridge: Cambridge Scholars

McKendrick, J.H., Horton, J. Kraftl, P. and Else, P. (2014). "Space for Playwork in Times of Austerity?” Journal of Playwork Practice 1: 79-118. 
Morton, K. (2011). “Cuts to children’s playgrounds revealed.” Nursery World, July 12, 2011. Available at: http://www.nurseryworld.co.uk/nursery-world/news/1105481/cuts-childrensplaygrounds-revealed [Accessed 22 November 2013].

NPFA, Children's Play Council and Playlink. (2000). Best Play: What play provision should do for children.

National Trust. (2013). Natural Childhood. Available at: http://www.nationaltrust.org.uk/whatwe-do/big-issues/nature-and-outdoors/natural-childhood [Accessed 26 November 2013].

Play Scotland. (nd). Getting it Right for Play. A toolkit to assess and improve local play opportunities. Roslin. Available at: http://www.playscotland.org/getting-it-right-for-play/ [Accessed 22 November 2013].

Play Wales. (nd). "Play Sufficiency.” Available at: http://www.playwales.org.uk/eng/sufficiency [Accessed 8 November 2013].

Scottish Government. (2013). Annual Report for Child Poverty Strategy for Scotland 2013. Edinburgh.

SkillsActive. (2010). Playwork People 4.

Smith, H. (2014) "Prospects for participatory research on wellbeing with playworkers and children at play,” Journal of Playwork Practice 1: 108-113

UNICEF. (2007). Child Poverty in Perspective: An Overview of Child Well-being in Rich Countries. A Comprehensive Assessment of the Lives and Well-being of Children and Adolescents in the Economically Advanced Nations. UNICEF Innocenti Research Centre Report Card 7. Florence. Available at: http://www.unicef-irc.org/publications/pdf/rc7_eng.pdf [Accessed 15 November 2013].

Ward, C. (1978). Child in the City. London: Architectural Press.

Woolvin, M. and Hardill, I. (2013). "Localism, voluntarism and devolution: experiences, opportunities and challenges in a changing policy context”, Local Economy 28.3: 275-290. 